$N 84-34808$

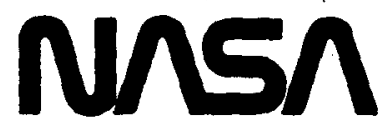

Technical Memorandum 86148

\title{
GEOPHYSICAL \\ INTERPRETATION OF \\ SATELLITE LASER RANGING \\ MEASUREMENTS OF \\ CRUSTAL MOVEMENT \\ IN CALIFORNIA
}

Steven C. Cohen

August 1984

National Aeronautics and

Space Administration

Goddard Space Flight Center

Greenbelt, Maryland 20771 
GEOPHYSICAL INTERPRETATION OF SATELLITE LASER RANGING MEASUREMENTS OF CRUSTAL MOVEMENT IN CALIFORNIA

August 1984

\author{
Steven C. Cohen \\ Geodynamics Branch \\ Goddard Space Flight Center \\ Greenbelt, Maryland 20771
}




\begin{abstract}
As determined by satellite laser ranging the rate of contraction of a 900 kilometer baseline between sites located near Quincy in northern California and San Diego in southern California is about $61-65 \mathrm{~mm} / \mathrm{yr}$ with a formal uncertainty of about $10 \mathrm{~mm} / \mathrm{yr}$ (Christodoulidis, et. al., 1984). The measured changes in baseline length are a manifestation of the relative motion between the North America and Pacific tectonic plates. This long baseline result is compared to measurements made by more conventional means on shorter baselines. Additional information based on seismicity, geology, and theoretical modelling is also analyzed. Deformation lying within a few tens of kilometers about the major faults in southern California accounts for most, but not all of the observed motion. Further motion is attributable to a broader scale deformation in southern California. Data suggesting crustal movements north of the Garlock fault, in and near the southern Sierra Nevada and local motion at an observatory are also critically reviewed. The best estimate of overall motion indicated by ground observations lies between 40 and $60 \mathrm{~mm} / \mathrm{yr}$. This lies within one or two standard deviations of that deduced by satellite ranging but the possibility of some unresolved deficit cannot be dismissed. The long time scale RM2 plate tectonic model of Minster and Jordan predicts a contraction between 47 and $53 \mathrm{~mm} / \mathrm{yr}$ depending on the extension rate of the Basin and Range. Thus the ground based observations, SLR results, and RM2 rates differ at about the $10 \mathrm{~mm} / \mathrm{yr}$ level and are consistent with one another within the data and model uncertainties.
\end{abstract}




\section{INTRODUCTION}

Space geodetic techniques for measuring the distances between observing sites have become increasingly reliable in the last decade and have now reached the level where geophysically interesting crustal deformations and movements can be monitored by both satellite laser ranging (SLR) and very long baseline interferometry (VLBI) techniques. For example a decade of VLBI observations between Haystack, MA and Owens Valley, CA have established that the baseline is stable at the few $\mathrm{mm} / \mathrm{yr}$ level (Ma, 1983). This result implies that either there is contemporary tectonic stability within the North American plate or there is a compensation of opposing motions across the numerous geophysical provinces spanned by the $3000 \mathrm{~km}$ baseline (these include the Appalachian Highlands, Interior Plains, Rocky Mountains, Colorado Plateau, Basin and Range, and Owens Valley Fault Zone).

An important and robust set of observations made with SLR techniques involves distance changes over a baseline in California connecting sites near Quincy to the northeast and San Diego in the southwest. The $900 \mathrm{~km}$ long baseline spans the boundary zone between the North America and Pacific plates in Southern California. Measurements have been made on this so-called SAFE (San Andreas Fault Experiment) baseline since 1972 beginning with observations on the Beacon Explorer-C satellite and continuing more recently (since 1979) with the Laser Geodynamics Satellite (Lageos).

A persistent contraction of the baseline has been detected since the first resurvey in 1974. During this time the satellite used in the observations has changed, the laser systems have been modified, and the observing sites have been moved. Despite these changes the observations indicate a sustained contraction. Although there have been some refinements in the deduced contraction rate since the first report of observed motion (Smith, 1974) and although there is still some degree of uncertainty concerning the absolute accuracy of the measurements, there seems to be little doubt that the relative motion of the North American and Pacific Plates is being observed in the measurements. The best current estimate of the contraction rate is about $61-65 \mathrm{~mm} / \mathrm{yr}$ with a formal standard deviation of less than $10 \mathrm{~mm} / \mathrm{yr}$ (Christodoulidis, et. al., 1984). A compilation of the changes in the baseline length and their variation with observing sites and satellites is shown in Figure 1. The observed motion is 
slightly higher than, but within one or two standard deviations of, the motion deduced on the basis of geological data in the RM2 model of Minster and Jordan (1978). Ignoring the effect of Basin and Range extension the Minster and Jordan estimate is $52.9 \pm 2.7 \mathrm{~mm} / \mathrm{yr}$; including the Basin and Range extension reduces the baseline contraction rate by 1 to $6 \mathrm{~mm} / \mathrm{yr}$ (Minster and Jordan, 1984). The purpose of this paper is to examine the SLR measurement in light of other geodetic, seismological, and geological information to determine whether the measurement is consistent with other data and to determine the likely distribution of crustal deformation over the extent of the line.

The setting for the SLR baseline is shown in Figure 2. The line spans a nearly $600 \mathrm{~km}$ long segment of the Sierra Nevada from near Quincy to the crossing of the Garlock fault north of Mojave. In the northern section it lies about $10 \mathrm{~km}$ west of the short Mohawk Valley Fault which ruptured in 1976. It then passes a few tens of kilometers to the west of Lake Tahoe, Mono Lake, and Mammoth Lakes. Continuing to the south the line lies forty to fifty kilometers west of the Ownes Valley and Sierra Nevada faults. However, the line approaches within about ten kilometers of the Sierra Nevada fault near its junction with the Garlock fault. There the Sierra Nevada fault has been offset to the west of its position further north. The SLR baseline crosses over the northly trending pre-Quaternary Kern Canyon fault at Isabella Reservoir and passes about 10-20 km east of the 1952 rupture of the White Wolf Fault.

South of the Garlock fault, the line passes through the Mojave desert and crosses the San Andreas fault near the northern terminus of the San Jacinto fault. The baseline continues through the San Gabriel mountains, passing near Mt. Baldy, then across the eastern extension of the San Gabriel Fault, and across the Cucamonga Fault. The Elsinor fault is crossed near Lake Elsinor as the line then continues south toward the Mexican border. Its southern terminus is in the Monument Peak-Otay Mountain region to the west of San Diego. A portion of the line is contained within the region of the supposed Southern California uplift of the 1970's.

In an attempt to understand the observed changes in the SLR baseline I have examined various possibilities for crustal deformation within different regions of California. Germane to the present paper are the following: 
1. Strain in the major fault zones of southern California. These faults include the Garlock, San Andreas, and San Jacinto, and Elsinor faults. There are also some potentially important lesser faults such as the San Gabriel and Cucamonga Faults.

2. A broad scale strain feature throughout Southern California south of the Garlock fault. The proposed feature is characterized by two principal axes. One lies approximately north-south and has a contraction rate of about 0.15 parts per million per year. The orthogonal component trends roughly east-west and has an extension rate of about 0.11 parts per million per year.

3. Possible fault related deformation north of the Garlock fault due to activity associated with the White Wolf, Breckenridge, and perhaps, the Kern Canyon Faults.

4. Deformation and tilting within the Sierra Nevada block. Microcracking on numerous small offset faults has occurred in the geologically recent past and may be continuing today presumably due to Basin and Range spreading to the east. Tilting and warping within the Sierra Nevada is also indicated by geodetic and geological data. Although the broadscale tilting of the Sierra Nevada is westward, evidence suggests some localized eastward tilting.

5. Local motion at the observatory sites.

\section{SOUTHERN CALIFORNIA FAULT ZONE DEFORMATIONS}

The US Geological Survey has several geodimeter networks that are located adjacent to major faults in Southern California. These networks, shown in Figure 3, are surveyed approximately annually. The most recent determinations of the strain rates deduced by least squares fitting to the observed baseline length changes are shown in Table I (Prescott, private communication, 1984; Savage, 1983). The results are expressed in a north-south, east-west coordinate system with positive values of $\dot{\boldsymbol{\epsilon}}_{11}$ representing east-west extension and negative values of $\dot{\boldsymbol{\epsilon}}_{22}$ representing north-south contraction. I have used these strain rates to estimate the deformation rates expected along the SAFE baseline azimuth as follows. First the elongation rate expected along the direction of the baseline (N24W) is calculated for each network using the tensor rotatation equations. Then the elongation rate is multiplied by a distance related to the grid size to get a relative velocity between end points of the 
grid. Appropriate velocities are added to get an estimate of the overall motion across several faults zones. Several assumptions are implicit in this approach. First, the strain rate is assumed uniform within a network but strain beyond the boundary of the network is excluded. Second, a translation of network results taken near one portion of a fault to the point where the SLR baseline crosses that fault is employed. For example, with the Garlock network I have assumed that the network results taken eastward of the point where the SLR baseline crosses the fault are also valid at the crossing location. Finally, an estimate must be made of the size of the network. For this estimate I have tried two possibilities: first, the largest distance across the network at the SLR azimuth and second a uniform distance of $100 \mathrm{~km}( \pm 50 \mathrm{~km}$ ) for all networks except the east-west trending Garlock grid (for which I choose 50 or $25 \pm \mathrm{km}$ ). These distances should be upper limits and in some cases a smaller value might be appropriate.

The assumed network sizes and deduced deformation velocities are shown in Table II. From the table we extract a velocity of 13-19 mm/yr across the Cajon network including the San Andreas fault and to a lesser extent the San Gabriel, Cucamonga and San Jacinto faults, about 7-13 mm/yr across the Anza network covering the San Jacinto and Elsinor faults, and 4-6 mm/yr across the Garlock network. The numbers should be reduced by the effects of the San Jacinto fault which are expected to be felt primarily to the east of the SLR baseline. The sum of these three contributions is more than 20 but less than $40 \mathrm{~mm} / \mathrm{yr}$. Although there is some uncertainty in this number, it appears that the motions deduced from the local networks are insufficient, by themselves, to explain the SLR observations. Other combinations of the local network results may be tried but they generally give lower and less satisfactory total motions. For example taking the Tehachapi network results to account for the crossing of the Garlock and San Andreas faults gives about $10 \mathrm{~mm} / \mathrm{yr}$ compared to the $20 \mathrm{~mm} / \mathrm{yr}$ for the combination of the Cajon and Garlock networks. The Salton network yields a contraction rate of $19 \mathrm{~mm} / \mathrm{yr}$ but a significant portion of this rate may come from the San Jacinto fault (Savage, et. al., 1979) which is not crossed by the SAFE baseline.

The variations in velocity deduced above are probably as much a function of the size of the networks chosen as geophysical differences. It is true that the elongation rates for the Palmdale, Cajon, 
and Salton networks which cross the San Andreas fault are among the larger rates and may reflect the dominate role played by the San Andreas fault in straining in Southern California. Nevertheless the deduced strain rate for the Techachapi network is within a factor of two of that for the Palmdale network despite the much larger extent of the former network. Thus two points emerge. First, straining in southern California appears to extend beyond the boundaries of the surveyed networks so that significant deformation may occur several tens of kilometers away from major fault traces. Second, as other workers have already noted, the strain rates may not vary that much from locale to locale. Therefore, for the present purposes, a uniform field approximation is an adequate representation of California south of the Garlock fault (Savage, 1983). Taking an average for the seven networks shown in Figure 3, the deduced contraction rate along the direction of the SLR baseline is $0.11 \mu$ strains/yr. Multiplying this number by the $350 \mathrm{~km}$ distance from the southern baseline terminus to a point about $30 \mathrm{~km}$ north of the Garlock fault gives a relative velocity of about $40 \mathrm{~mm} / \mathrm{yr}$. This number is a bit closer to the SLR result, particularly given the uncertainties in the data and its interpretation. Nevertheless there remains a distinct possibility that the SAFE contraction rate is higher than can be explained by the phenomena discussed so far. Therefore it is important to consider whether deformations are likely elsewhere along this baseline.

Before discussing the possibilities that there are other locales for crustal movement, I wish to discuss the mechanisms which could give rise to the suggested broad scale straining in southern California and the further evidence for departures from purely elastic strain accumulation. A dislocation extending to the $15 \mathrm{~km}$ seismogenic depth in an elastic halfspace produces a strain field localized within a few tens of kilometers from the fault. However distributed yielding, deformation associated with multiple deep or near surficial faults, and subsurface viscoelastic flow below will all produce broader fields. To test the degree to which elastic strain models explain or fail to explain current strain rates I consider, in Figure 4, how lines of constant shear strain rate depend on fault depth and the relative velocity of the two plates separated by the fault. The calculations assume an infinitely long fault in an elastic halfspace. Line segments lying within the boxed area are shear strain rates that are consistent with an elastic earth relative plate velocities between 30 and $60 \mathrm{~mm} / \mathrm{yr}$, and fault depths 
between 10 and $30 \mathrm{~km}$. The observed shear strain, derived from the Palmdale network is about 0.15 $\mu$ strain/yr. This result does not quite fit within the box, but is nearly consistent with a velocity of 3 $\mathrm{cm} / \mathrm{yr}$ and a fault depth of $30 \mathrm{~km}$. By contrast, if we assume a velocity of $3.5 \mathrm{~cm} / \mathrm{yr}$ and a fault depth of $15 \mathrm{~km}$ the expected shear strain rate is $0.3 \mu \mathrm{strain} / \mathrm{yr}$, twice the currently observed value. Thus the data weakly suggest departure from elastic shear accumulation on a single fault. However, by considering elastic dislocation theory for single and multiple faults Savage (1983) was able to find approximate fits for certain displacements derived from single geodimeter networks.

Further theoretical consideration of the strain rates averaged over two different distances shows that the ratio of the shear strain rates depends on two quantities: the ratio of the two distances orthogonal to the fault and the ratio of one of distances to the fault depth. If the smaller distance is defined by the Palmdale network then the data for the Tehachapi, Los Padres, Cajon, and Anza networks are consistent with an elastic model with fault depths ranging between less than 15 to somewhat over $30 \mathrm{~km}$. In obtaining these results I have ignored the complicating effects of non-shearing components of the strain rate tensor, different fault orientations, and multiple faults. For example, the Tehachapi network is a broad grid that includes the Palmdale network within its boundaries but also contains a portion of the Garlock fault within its domain. The Anza network is completely to the west of the San Andreas fault but contains both the Elsinor and San Jacinto Faults. The latter fault may be the dominant strand of the San Andreas system in this region. The deduced fault depths are marginally higher than expected on the basis of seismic focal depth data, but given the many simplifications the agreement is not bad. The Salton Sea results give much larger faults depths, perhaps because of the multiple active faults within this region.

Since elastic models predict that strain rates are constant with time and that the strain field is confined to the vicinity of a fault, a comparison of geodetic results taken at different times can be instructive. Historic multiangulation data suggest broader strain fields than indicated by current geodimeter results (Thatcher, 1979; Savage, 1983). Furthermore anelastic models also predict that the strain rates near the fault subsequent to an earthquake are much higher than indicated by elastic calculations and become lower thereafter; this decrease in strain rates has been reported by Thatcher 
(1975) for the San Francisco earthquake and is suggested by both Thatcher (1979) and Savage (1983) for southern California. We conclude from the discussion in this and the preceeding paragraphs that an elastic model is marginal for explaining fault depths and the width of the observed strain fields, and is even weaker in explaining the magnitude and time dependence of the strain rate.

Snay and his colleagues at the National Geodetic Survey have been working on the REDEAM (Regional Earth Deformation Model) Project as a method of incorporating a variety of geodetic data into a model of crustal motion. The method divides a broad area such as California into a number of regions as shown in Figure 5. These regions in turn are divided into a number of smaller districts. The district boundaries are fault traces or other physical boundaries in some cases but other, purely geographic, boundaries are also employed. Within each district geodetic data are used in a least squares adjacement for constant velocity secular motion of the latitude and longitude of observing points. In addition episodic terms representing individual earthquakes are derived. The data types include angulation measurements, astronomical azimuths, taped distances, and geodimeter observations. Snay (private communication, 1984) has derived the REDEAM prediction for the secular deformation rate between Quincy and Otay Mountain, essentially the SAFE baseline. The rate is $\mathbf{5 8 . 3}$ $\mathrm{mm} / \mathrm{yr}$. This number agrees quite well with the SLR result and is intermediate between the SLR result and that deduced on the basis of the geodimeter data for southern California alone. However several precautionary observations must be made. The REDEAM solution spans eight regions, four essentially north of the Garlock fault, and four primarily to the south. Over the four southern regions alone the contraction rate is $48.1 \mathrm{~mm} / \mathrm{yr}$. This number is constrained largely by geodimeter data; therefore, the general agreement with that data is not surprising. The formal uncertainty in the contraction rates are modest. For example the contraction rate for the $\mathbf{5 0}$ kilometer segment in the San Bernadino region is $8.8 \pm 1.2 \mathrm{~mm} / \mathrm{yr}$. The fractional contraction rates in the four southern regions are rather uniform ranging from 0.11 parts per million in the San Diego and northeastern Los Angeles regions to 0.18 parts per million in the southwestern San Bernadino area. This is consistent with the uniform strain approximation discussed above. The REDEAM solution for the four northern regions is -10.2 $\mathrm{mm} / \mathrm{yr}$. This result is subject to a much greater degree of uncertainty. Most of the data is derived 
from historic measurements not taken for research purposes. The formal uncertainty in the northern segments is illustrated by the rate for the Ukiah region which is $+10.8 \pm 9.8 \mathrm{~mm} / \mathrm{yr}$. The data sets for the northern regions are dominated by angulation measurements. Thus the shear rates are better determined than scale. A second solution for the four northern segments in which dilatation was held fixed at zero gave $-3.2 \mathrm{~mm} / \mathrm{yr}$ for the contraction rate. Despite the uncertainties it is interesting to note that the largest contraction rate, within these northern segments, is in the southernmost region. (in fact, in the unconstrained solution, the rates change monotonically from south to north, with extension occurring in the two northly regions.) The contraction rate deduced across this Sierra Nevada region is $23.2 \mathrm{~mm} / \mathrm{yr}$ or $17.0 \mathrm{~mm} / \mathrm{yr}$ when the dilatation is set equal to zero. Furthermore, near the boundary of the Sierra Nevada segment with the Bakersfield and Barstow districts, triangulation results reported by Thatcher (1979) showed very large, poorly constrained, shears in the 9 years subsequent to the Kern County earthquake $(1952, M=7.2)$. This triangulation data spanned the Breckenridge fault beyond the eastward extent of the rupture of the White Wolf Fault. Thus there is some suggestion of crustal deformation near the southern Sierra Nevada, but the evidence is not very strong. I will have more to say about fault related crustal deformation north of the Garlock fault in the next section.

\section{DEFORMATION IN THE SIERRA NEVADA AND NEAR THE WHITE WOLF FAULT}

The Sierra Nevada is generally regarded as an uplifted and tilted block bounded by major faults, and not subject to a great deal of internal deformation. There is, however, evidence for pervasive, small scale crustal deformation in the recent geological past which may be continuing in the present era. Lockwood and Moore (1979) have studied extensive microfaulting in the Sierra Nevada for regions extending from near the SAFE baseline eastward. They find numerous left lateral microfaults trending primarily NE to ENE and a lesser number of right lateral microfaults trending NW to NE. Along a $2.2 \mathrm{~km}$ line within a small region near Mount Abbot, Lockwood and Moore discovered 476 joints. Of these, 427 joints showed left lateral motion with a cumulative offset of 76.7 meters and 42 joints showed right lateral offset with a cumulative offset of 0.57 meters. The strain field deduced 
from the field observations with the additional assumption of no dilatation is an extension of 0.023 $\mu$ strains at N61W and an equal magnitude contraction at N29E. This gives an elongation along the SLR azimuth of $0.0077 \mu$ strains. Assuming that the extension has proceeded at a constant rate for 70 million years gives an elongation rate well less than $1 \mathrm{~mm} / \mathrm{yr}$ over the entire $580 \mathrm{~km}$ extent of the SLR baseline in the Sierra Nevada. This conclusion is unaltered when the assumption of no dilatation is replaced by that of uniaxial extension. Thus microfaulting appears to have no effect on the SLR data.

Vertical motion associated with westward block tilting of the Sierra Nevada is well known (particularly from geological data) but it also appears that some localized motions deviate from the general trend. The generally westward tilting associated with relative block uplift on the eastern bounding faults of the Sierra Nevada should have little effect on the predominately north-south SLR baseline. Geodetic data in the interior of the mountains is very limited, however, some leveling results have been reported by West and Wood (1979) for a line near the northern terminus of the SAFE baseline. A second order leveling line that runs from Richvale in the Central Valley to Kiddie just north of the Quincy site was surveyed in 1932 and again in 1934. The data show no net motion to the west of the Rich Bar fault located $30 \mathrm{~km}$ to the west of Kiddie. However from the Rich Bar Fault to Kiddie there is an apparent eastward tilting resulting in a lowering of the Kiddie site relative to the Rich Bar Fault of $20 \mathrm{~mm} / \mathrm{yr}$. While this motion is thought to be dominately orthogonal to the SSE trend of the SLR baseline, the possibility of some motion along the baseline cannot be excluded. Although the magnitude of the tilting appears to be significantly above the noise level in the survey (despite the second order accuracy of the leveling) tilting alone would not necessarily produce horizontal motion even at the $1 \mathrm{~mm} / \mathrm{yr}$ level. Furthermore leveling data in mountainous area are subject to serious unadjusted errors and must be considered with great skepticism. Unfortunately there are no horizontal survey data to indicate whether significant lateral deformation accompanies the apparent tilting. Additional leveling data further south in the Sierra Nevada was reported for a line running from Riverbank to Strawberry, California. The latter location is just to the east of the SAFE baseline. First order leveling on this line between 1932 and 1957 indicated a $100 \mathrm{~mm}$ eastward tilting of Strawberry 
relative to Sonara on the east end of the Melones fault zone. Even further south second order leveling was conducted on a line between Merced and Yosemite in 1935 and 1947. These data suggest a 90 $\mathrm{mm}$ local uplift of the Sierra Nevada mountains about $10 \mathrm{~km}$ west of the survey line's junction with the SAFE baseline. An examination of the vertical coordinates for the SLR Quincy site (shown in Table III) reveals that there are fluctuations greater than the baseline fluctuations so no significant vertical motion can be deduced as of yet from the laser data. I conclude that the leveling data provides tantilizing suggestions of vertical motion, but there is no good evidence for significant movement, particularly in a horizontal sense, along the SAFE baseline throughout most of the Sierra Nevada.

Two major fault zones other than those discussed in the previous section have been considered as possible sources of crustal deformation along the SLR baseline. The White Wolf fault is a left lateral, reverse thrust feature which ruptured during the 1952 Kern County earthquake. The rupture terminated 10 to $20 \mathrm{~km}$ to the west of the SAFE baseline. There is no geological evidence to suggest that the fault extends any farther to the east. We have used several elastic dislocation models to estimate the crustal deformation along the SLR baseline due to strain accumulation on the White Wolf Fault. The fault parameters are taken from the work of Stein and Thatcher (1981) and include dip angles between 20 and 75 degrees, depths of faulting from the surface to at most 20 kilometers, various fault strikes and fault lengths. In all cases we find that the rate of deformation is not much more than $1 \mathrm{~mm} / \mathrm{yr}$ of contraction. However as indicated earlier the multiangulation results hint at large strain rates to the east of White Wolf fault in the ten years following the Kern County earthquake and the REDEAM model predicts secular strain rates in the nearby Sierra Nevada region of around $20 \mathrm{~mm} / \mathrm{yr}$. As for the Kern County fault, the geological data imply that the fault has not suffered a major rupture for over one million years. However the seismic data provided by Astiz and Allen (Figure 6) do indicate that this old feature is still a source of some activity. The level of activity for 1981 there and near the eastern end of the 1952 White Wolf Fault rupture was greater than at some locales on the San Andreas Fault. Additional scattered seismicity extends considerably to the north of the White Wolf Fault. To the best of our knowledge there are no major events in these areas within historical times, but the possibility of tectonic deformation in these various regions cannot be dismissed. 


\section{CONCLUDING REMARKS}

Fault related crustal deformation south of the Garlock fault is the major contributor to the SLR observed baseline shortening. The region of significant straining extends beyond the bounds of the existing geodimeter networks and may include much of Southern California. Between 10 and 30 $\mathrm{mm} / \mathrm{yr}$ of SLR determined crustal shortening can not be explained by the geodimeter data for the southern California networks alone; however, most of the residual can be explained by regional deformation outside of the geodimeter network. Other possibilities include local strains significantly greater than the regional average, deformation in the San Gabriel mountains, and movement south of the Elsinor fault. Although deformation to the north of the Garlock fault is less than it is to the south, we cannot exclude the possibility of horizontal motions ranging from a few $\mathrm{mm} / \mathrm{yr}$ to $10 \mathrm{~mm} / \mathrm{yr}$. Of particular concern are possibilities for deformation to the east of the White Wolf Fault. Strain rates as small as a few parts in $10^{8}$ per year, if pervasive throughout the Sierra Nevada, would be significant for the SAFE baseline, but such deformation seems unlikely. Microfaulting measured in the central Sierra Nevada causes an insignificant extension of the SLR baseline and tilting is unlikely to produce much effect. Local movements of the observatories are thought to be small but they are not well known. The present SAFE measurements in California are roughly consistent with, but somewhat larger than, both the REDEAM geodetic model, and the RM2 geologic plate motion model of Minster and Jordan (1978). Future SLR measurements will refine the determination of the contraction rate and may reduce the residual differences, increase them, or indicate significant time variations in the contraction rate. 


\section{ACKNOWLEDGEMENTS}

I acknowledge, with gratitude, the generous contributions of several individuals who provided information used in this paper. The USGS geodimeter data was provided by Will Prescott. The REDEAM results were generated by Richard Snay. A summary of the SLR baseline measurements was given to me by Demos Christodoulidis. Additional SLR data was provided Steven Klosko, Ron Kolenkiewicz and David Smith. Discussions with each of these individuals has strengthened my understanding of the various data; however, the speculations contained within this paper are my responsibility alone. 


\section{REFERENCES}

Astiz, L., and C. R. Allen, "Seismicity of the Garlock Fault, California," Bull. Seismol. Soc. Am., 73, 1721-1734, 1983.

Christodoulidis, D. C., D. E. Smith, R. Kolenkiewicz, S. M. Klosko, P. J. Dunn, and M. H. Torrence, "Observing Tectonic Plate Motions and Deformation from Satellite Laser Ranging," J. Geophys. Res., in press, 1984.

King, N. E., and J. C. Savage, "Strain-rate Profile Across the Elsinor, San Jacinto, and San Andreas Faults near Palm Springs, California, 1973-81," Geophys. Res. Lett., 10, 55-57, 1983.

Lockwood, J. P., and J. G. Moore, "Regional Deformation of the Sierra Nevada, California on Conjugate Microfault Sets," J. Geophys. Res., 84, 6041-6049, 1979.

Ma, C., T. A. Clark, J. W. Ryan, B. R. Schupler, “Geodesy by Radio Interferometry,” Tectonic Stability within the Continental United States," EOS, Trans. Am. Geophys. U., 64, 210, 1984.

Minster, J. B., and T. H. Jordan, "Present-Day Plate Motions," J. Geophys. Res., 83, 5531-5554, 1978.

Minster, J. B., and T. H. Jordan, "Vector Constraints on Quaternary Deformation of the Western United States East and West of the San Andreas Fault," Tectonics and Sedimentation along the California Margin, Crouch, J. K., and S. B. Bachman, eds., Pac. Sect., S.E.P.M., 1984.

Savage, J. C., "Strain Accumulation in Western United States," Ann. Rev. Earth Planet. Sci., 11, $11-43,1983$.

Snay, R. A., M. W. Cline, and E. L. Timmerman, "Horizontal Crustal Deformation Models for California from Historical Geodetic Data," presented at "International Symposium on Recent Crustal Movements of the Pacific Region," Wellington, New Zealand, 1984.

Stein, R. S., and W. Thatcher, "Seismic and Aseismic Deformation Associated with the 1952 Kern County, California Earthquake and Relationship to the Quaternary History of the White Wolf Fault," J. Geophys. Res., 86, 4913-4928, 1981.

Thatcher, W., "Strain Release Mechanism of the 1906 San Francisco Earthquake," Science, 184, $1283-1285$. 
Thatcher, W., "Horizontal Deformation from Historic Geodetic Measurement in Southern California," J. Geophys. Res., 84, 2351-2370, 1979.

West, D. O., and J. N. Alt, "Analysis of Recent Crustal Movements in the Central and Northern Sierra Nevada, California, Using Repeated Geodetic Leveling Data," Tectonophysics, 52, 239-248, 1979. 
Table I

Strain Rates (in units of $\mu$ strain/yr) for southern California geodimeter networks (Prescott, private communication, 1984).

Network Time

ANZA 74.0-83.7

$\dot{\epsilon}_{11}$ $\dot{\epsilon}_{22}$ $\dot{\boldsymbol{\epsilon}}_{12}$

CAJON

$74: 3-82.8$

$0.10 \pm 0.01$

$-0.17 \pm 0.01$

$0.01 \pm 0.01$

GARLOCK

$73.2-82.4$

$0.12 \pm 0.03$

$-0.17 \pm 0.02$

$0.09 \pm 0.02$

LOS PADRES

73.8-82.5

$0.04 \pm 0.03$

$-0.14 \pm 0.02$

$-0.05 \pm 0.01$

PALMDALE

$71.6-83.4$

$0.10 \pm 0.02$

$-0.16 \pm 0.02$

$0.01 \pm 0.01$

SALTON

72.9-83.3

$0.16 \pm 0.01$

$-0.13 \pm 0.02$

$0.12 \pm 0.01$

TEHACHAPI

$73.6-82.9$

$0.16 \pm 0.01$

$-0.19 \pm 0.04$

$-0.03 \pm 0.00$

$0.11 \pm 0.02$

$-0.11 \pm 0.01$

$0.05 \pm 0.01$ 


\section{Table II}

Elongation rates and rates of change in baseline length deduced from Southern California geodimeter network data. The distances used in calculating motion across individual grids are shown in under the baseline rates.

\begin{tabular}{|c|c|c|c|c|}
\hline \multirow{2}{*}{$\frac{\text { NETWORK }}{\text { ANZA }}$} & \multirow{2}{*}{$\begin{array}{l}\text { FAULTS } \\
\text { SAN JACINTO } \\
\text { ELSINOR }\end{array}$} & \multirow{2}{*}{$\begin{array}{l}\text { ELONGATION RATE } \\
\frac{\left(\mathrm{N} 24^{\circ} \mathrm{W}\right)}{-0.13 \times 10^{-7}}\end{array}$} & \multicolumn{2}{|c|}{ BASELINE RATE } \\
\hline & & & $\begin{array}{l}-7 \mathrm{~mm} / \mathrm{yr} . \\
(57 \mathrm{~km})\end{array}$ & $\begin{array}{l}-13 \mathrm{~mm} / \mathrm{yr} . \\
(100 \mathrm{~km})\end{array}$ \\
\hline CAJON & $\begin{array}{l}\text { SAN ANDREAS } \\
\text { SAN GABRIEL } \\
\text { SAN JACINTO }\end{array}$ & -0.19 & $\begin{array}{l}-13 \mathrm{~mm} / \mathrm{yr} . \\
(67 \mathrm{~km})\end{array}$ & $\begin{array}{l}-19 \mathrm{~mm} / \mathrm{yr} \\
(100 \mathrm{~km})\end{array}$ \\
\hline GARLOCK & GARLOCK & -0.07 & $\begin{array}{l}-6 \mathrm{~mm} / \mathrm{yr} \\
(75 \mathrm{~km})\end{array}$ & $\begin{array}{l}-4 \mathrm{~mm} / \mathrm{yr} \\
(50 \mathrm{~km})\end{array}$ \\
\hline LOS PADRES & SAN ANDREAS & -0.12 & $\begin{array}{l}-13 \mathrm{~mm} / \mathrm{yr} . \\
(105 \mathrm{~km})\end{array}$ & $\begin{array}{l}-12 \mathrm{~mm} / \mathrm{yr} . \\
(100 \mathrm{~km})\end{array}$ \\
\hline PALMDALE & SAN ANDREAS & -0.17 & $\begin{array}{l}-3 \mathrm{~mm} / \mathrm{yr} \\
(14 \mathrm{~km})\end{array}$ & $\begin{array}{l}-17 \mathrm{~mm} / \mathrm{yr} . \\
(100 \mathrm{~km})\end{array}$ \\
\hline SALTON & $\begin{array}{l}\text { SAN ANDREAS } \\
\text { SAN JACINTO } \\
\text { ELSINOR } \\
\text { IMPERIAL }\end{array}$ & -0.11 & $\begin{array}{l}-19 \mathrm{~mm} / \mathrm{yr} \\
(171 \mathrm{~km})\end{array}$ & \\
\hline TEHACHAPI & $\begin{array}{l}\text { SAN ANDREAS } \\
\text { GARLOCK }\end{array}$ & -0.11 & $\begin{array}{l}-9 \mathrm{~mm} / \mathrm{yr} . \\
(86 \mathrm{~km})\end{array}$ & $-11 \mathrm{~mm} / \mathrm{yr}$ \\
\hline AVERAGE & & -0.13 & & $\begin{array}{l}-42 \mathrm{~mm} / \mathrm{yr} \text {. } \\
(320)\end{array}$ \\
\hline
\end{tabular}


Table III

Vertical coordinate determinations of Quincy SLR site.

Station Number

7051

7051

7109

7109

\section{Occupation Time}

1979

1981

1981

1982
Height Above Reference Elipsoid

1052.990 meters

1052.89 meters

1099.17 meters

1099.24 meters 


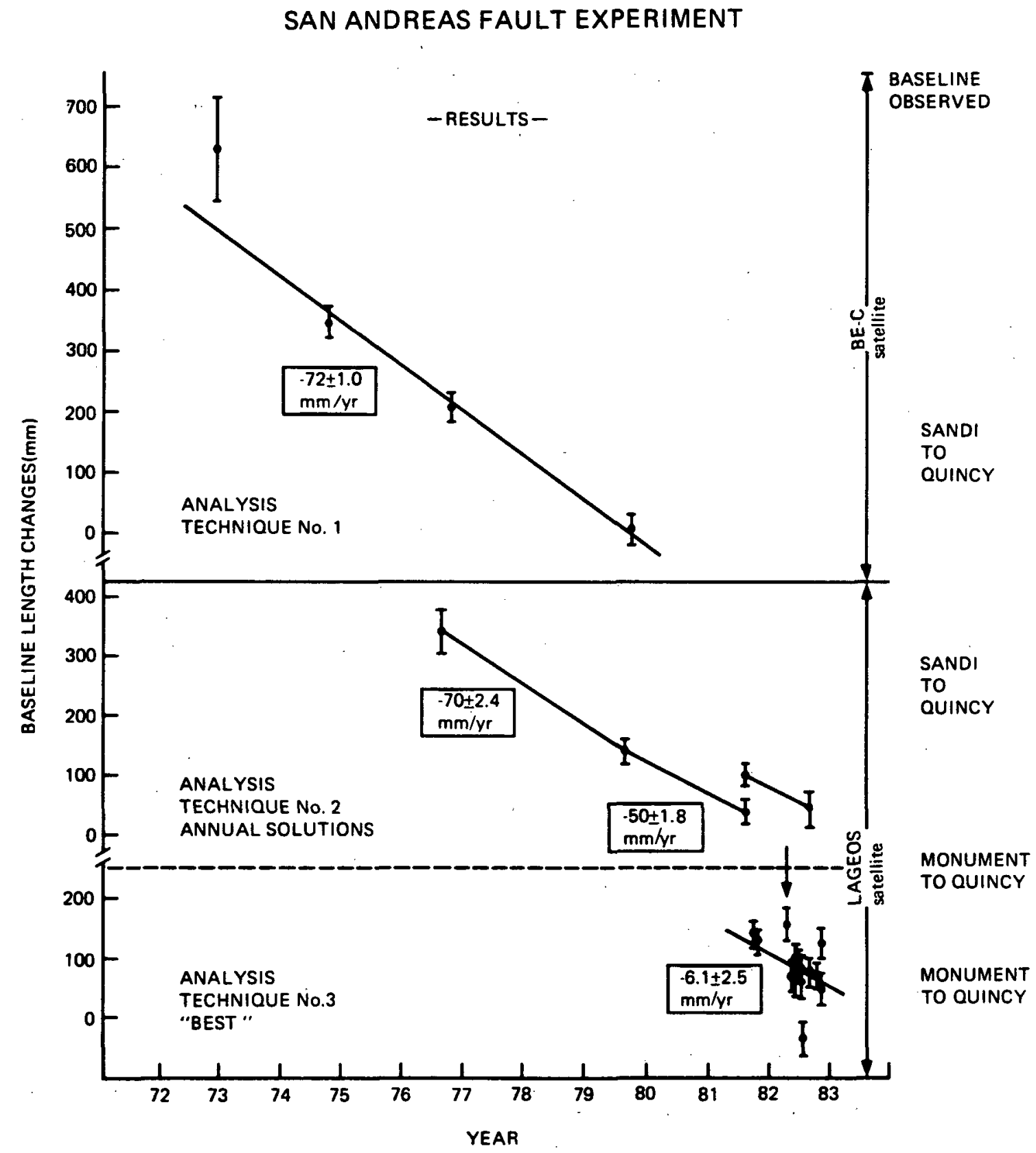

Figure 1: SLR determined baseline changes 1972-1983. The deduced rates shown in the figure use the analysis techniques discussed by Christodoulidis, et. al (1984). The first four observations used the Beacon Explorer-C satellite; subsequent measurements used Lageos. The southern California site was changed from Sandi to Monument Peak in 1981. 


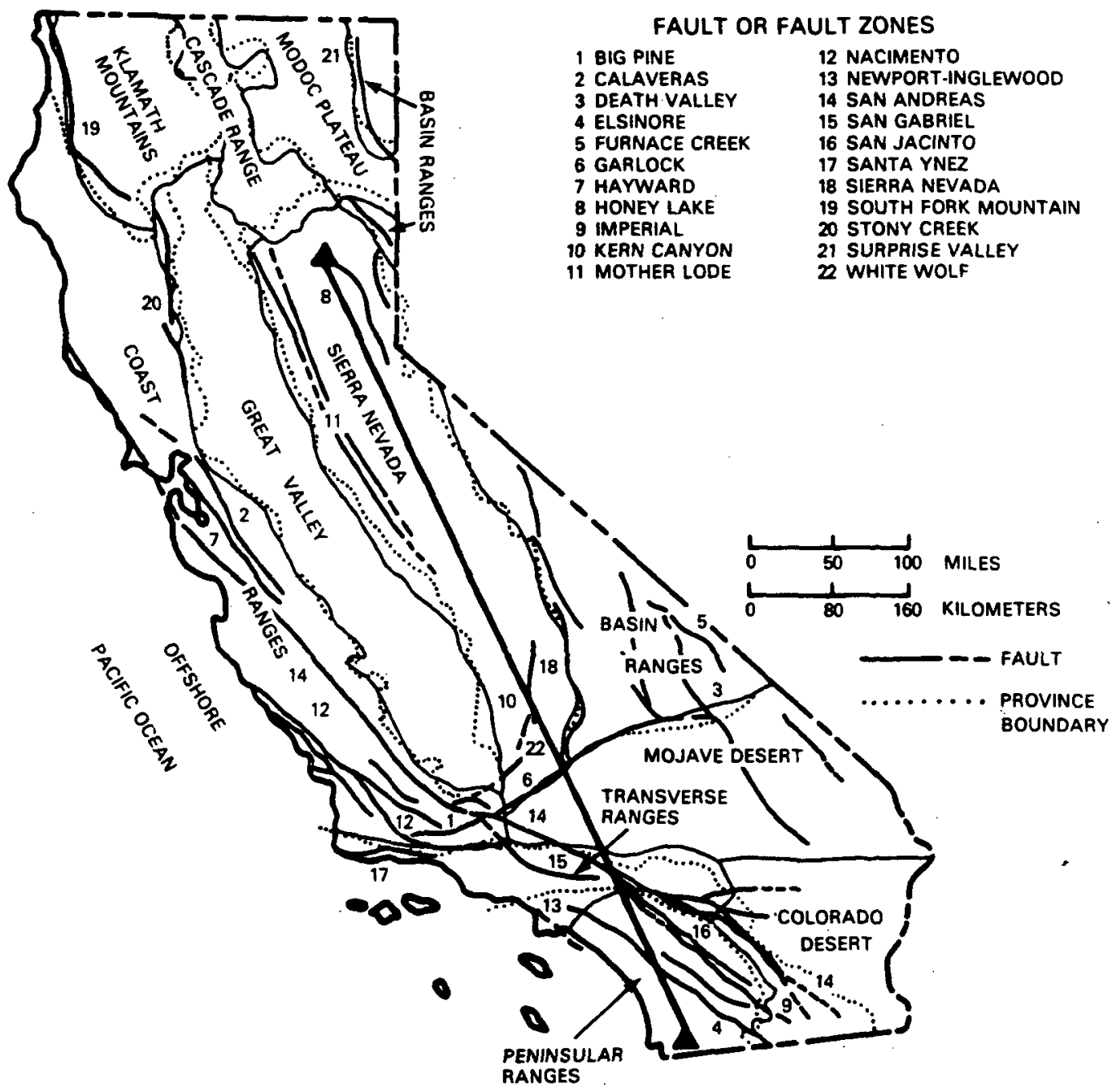

Figure 2: Geomorphic provinces and major faults traversed by SAFE baseline. The base map is adopted from Norris and Webb (1976). 


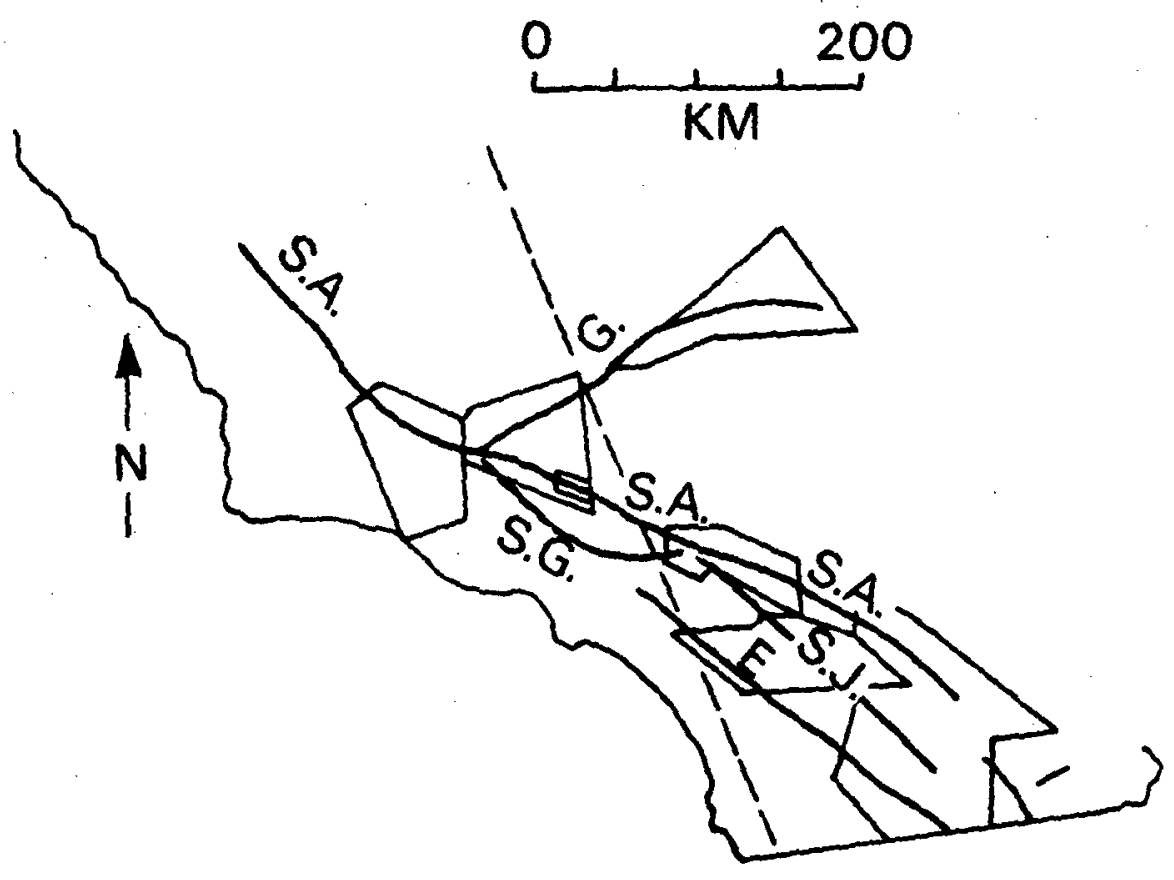

Figure 3: Multilateration geodimeter networks operated by US Geological Survey in Southern California. 


\section{SHEAR STRAIN RATE}

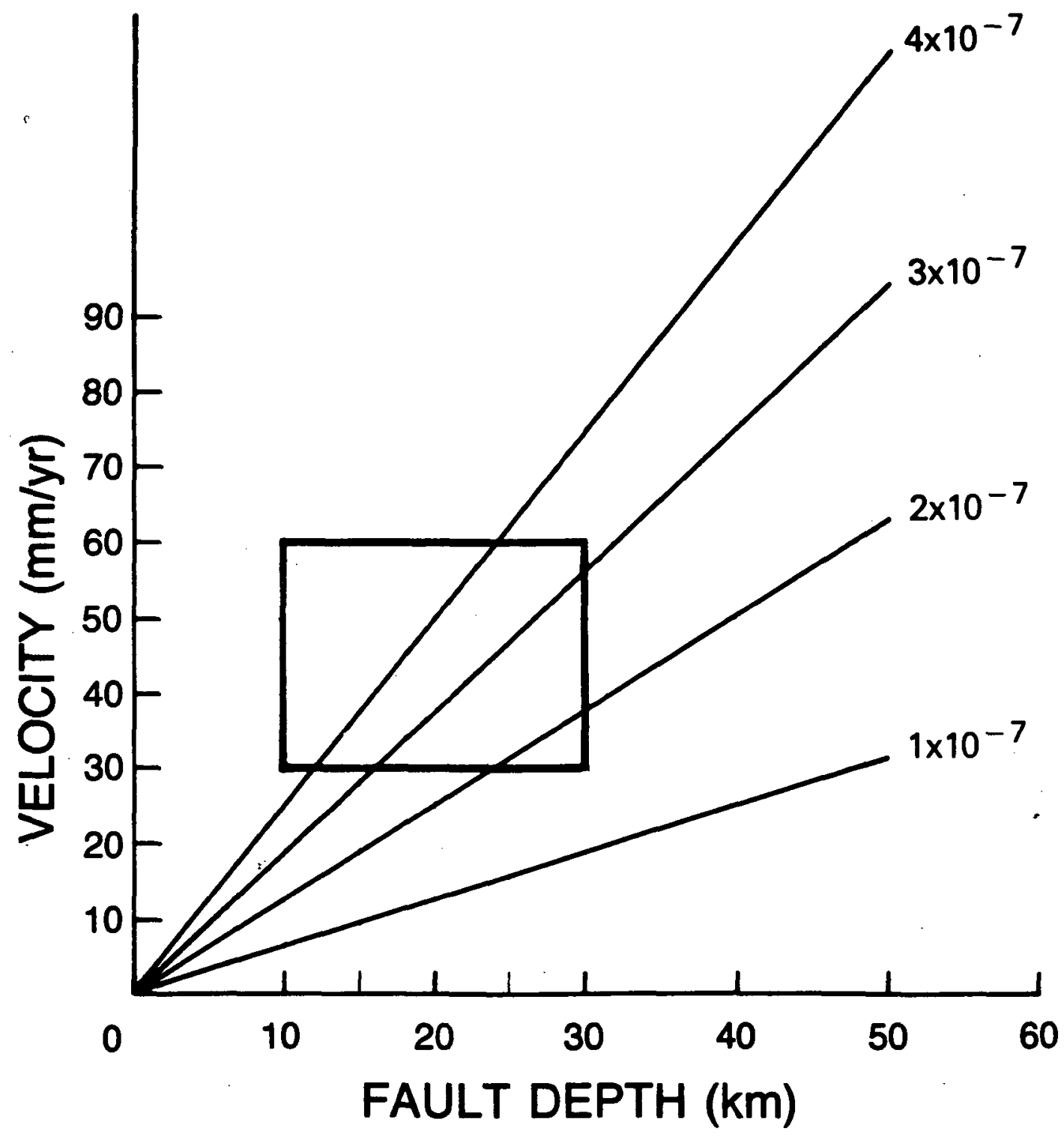

Figure 4: Shear rate contours shown as a function of fault depth and relative plate velocity for an infinitely long fault in an elastic half-space. 


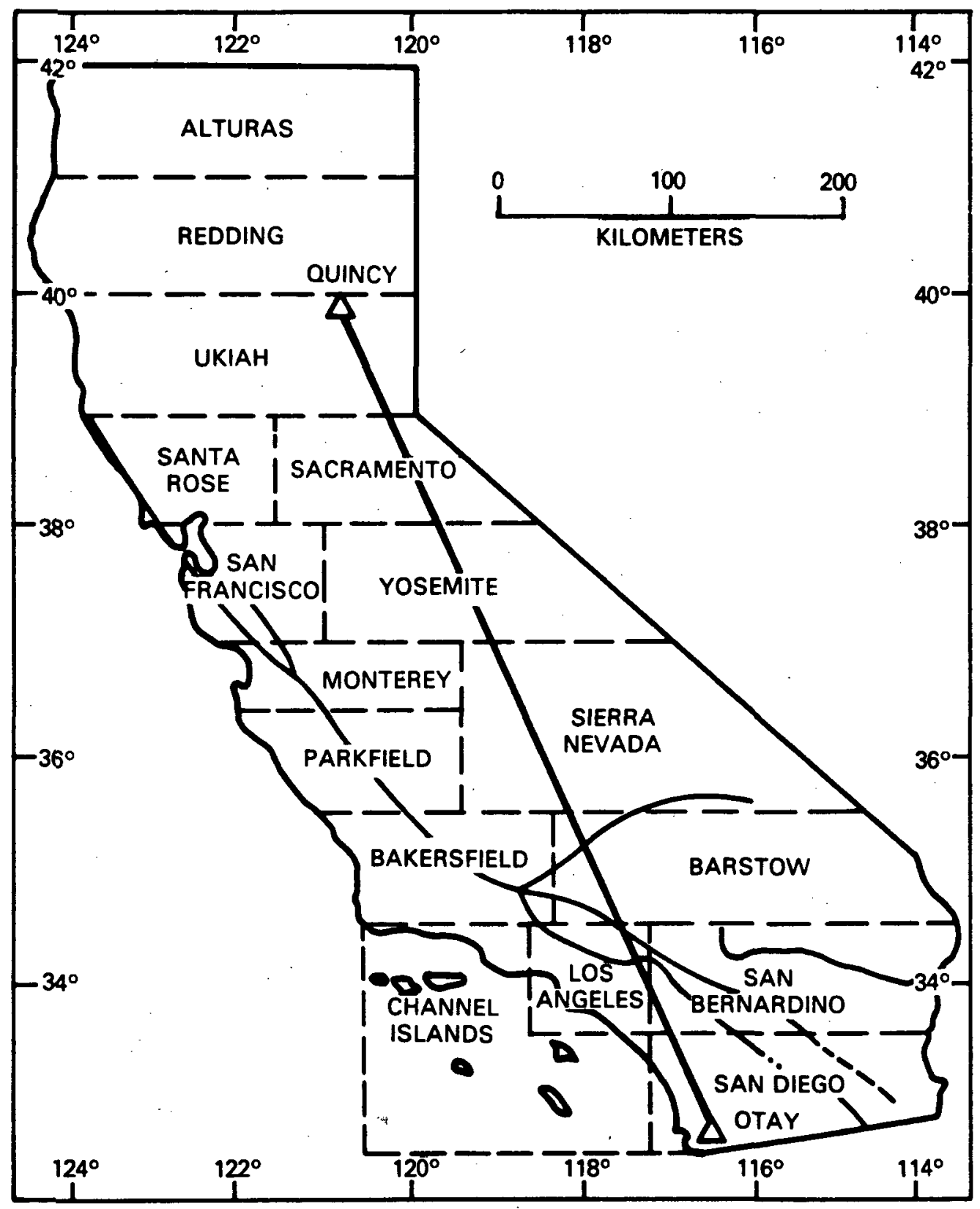

Figure 5: REDEAM regions for California (Snay, et. al., 1984). 


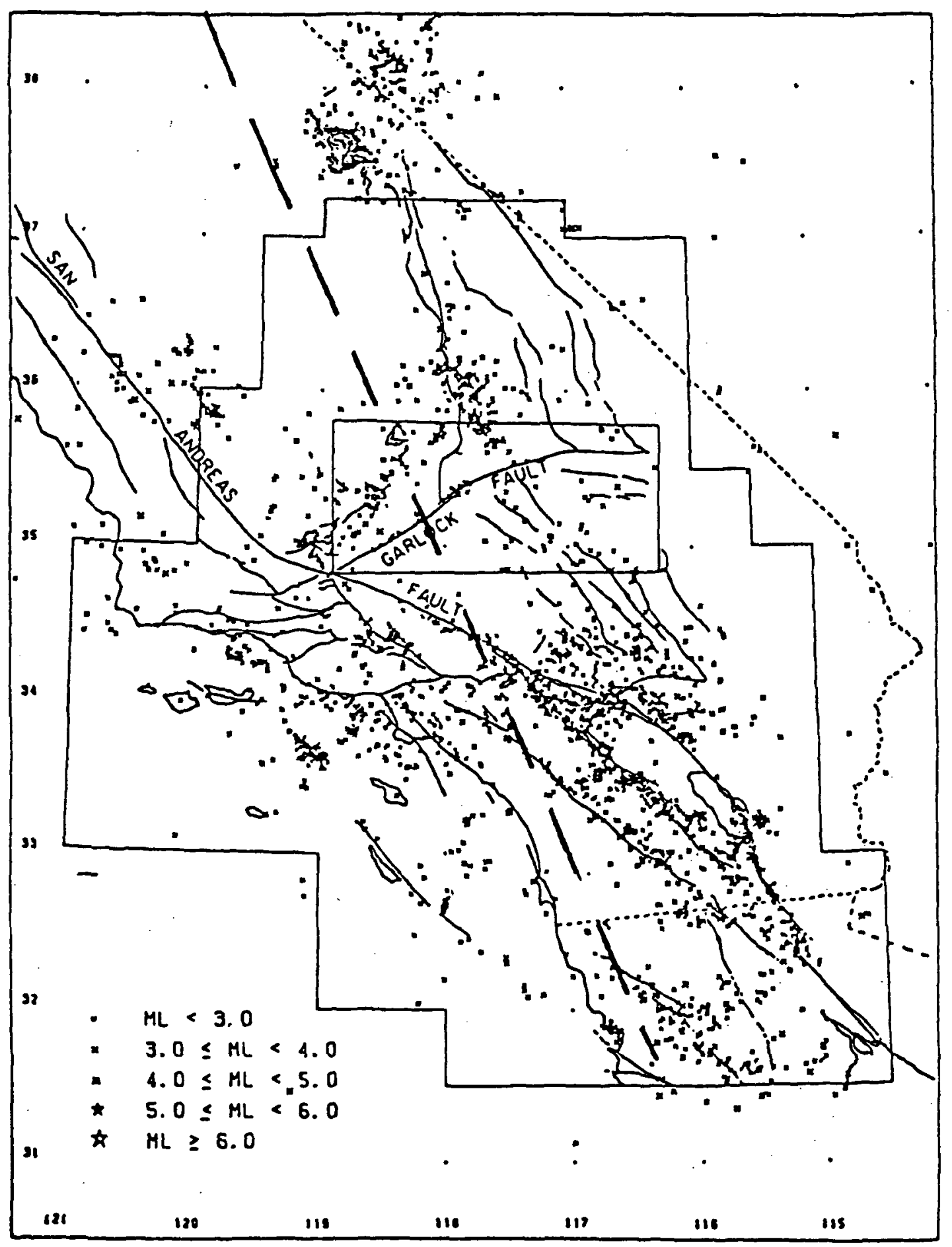

Figure 6: Seismicity in Southern California, 1981 (Astiz and Allen, 1983). 


\begin{tabular}{|c|c|c|}
\hline $\begin{array}{l}\text { 1. Report No. } \\
\text { TM86148 }\end{array}$ & 2. Government Accession No. & 3. Recipient's Catalog No. \\
\hline \multirow{2}{*}{\multicolumn{2}{|c|}{$\begin{array}{l}\text { 4. Title and Subtitle } \\
\text { INTERPRETATION OF SATELLITE LASER RANGING } \\
\text { MEASUREMENTS OF CRUSTAL MOVEMENT } \\
\text { IN CALIFORNIA }\end{array}$}} & $\begin{array}{l}\text { 5. Report Date } \\
\text { August } 1984\end{array}$ \\
\hline & & $\begin{array}{l}\text { 6. Performing Organization Code } \\
621\end{array}$ \\
\hline \multicolumn{2}{|c|}{$\begin{array}{l}\text { 7. Author(s) } \\
\text { Steven C. Cohen }\end{array}$} & 8. Performing Organization Report No. \\
\hline \multirow{3}{*}{\multicolumn{2}{|c|}{$\begin{array}{l}\text { 9. Performing Organization Name and Address } \\
\text { Geodynamics Branch } \\
\text { Goddard Space Flight Center } \\
\text { Greenbelt, Maryland } 20771\end{array}$}} & 10. Work Unit No. \\
\hline & & 11. Contract or Grant No. \\
\hline & & \multirow[t]{2}{*}{ 13. Type of Report and Period Covered } \\
\hline \multirow{2}{*}{\multicolumn{2}{|c|}{$\begin{array}{l}\text { 12. Sponsoring Agency Name and Address } \\
\text { Geodynamics Branch } \\
\text { Goddard Space Flight Center } \\
\text { Greenbelt, Maryland } 20771\end{array}$}} & \\
\hline & & 14. Sponsoring Agency Code \\
\hline
\end{tabular}

15. Supplementary Notes

16. Abstract

As determined by satellite laser ranging the rate of contraction of a 900 kilometer baseline between sites located near Quincy in northern California and San Diego in southern California is about 61-65 mm/yr with a formal uncertainty of about $10 \mathrm{~mm} / \mathrm{yr}$ (Christodoulidis, et. al., 1984). The measured changes in baseline length are a manifestation of the relative motion between the North America and Pacific tectonic plates. This long baseline result is compared to measurements made by more conventional means on shorter baselines. Additional information based on seismicity, geology, and theoretical modelling is also analyzed. Deformation lying within a few tens of kilometers about the major faults in southern California accounts for most, but not all of the observed motion. Further motion is attributable to a broader scale deformation in southern California. Data suggesting crustal movements north of the Garlock fault, in and near the southern Sierra Nevada and local motion at an observatory are also critically reviewed. The best estimate of overall motion indicated by ground observations lies between 40 and $60 \mathrm{~mm} / \mathrm{yr}$. This lies within one or two standard deviations of that deduced by satellite ranging but the possibility of some unresolved deficit cannot be dismissed. The long time scale RM2 plate tectonic model of Minster and Jordan predicts a contraction between 47 and $53 \mathrm{~mm} / \mathrm{yr}$ depending on the extension rate of the Basin and Range. Thus the ground based observations, SLR results, and RM2 rates differ at about the $10 \mathrm{~mm} / \mathrm{yr}$ level and are consistent with one another within the data and model uncertainties.

\begin{tabular}{|c|c|c|c|c|}
\hline \multicolumn{2}{|c|}{$\begin{array}{l}\text { 17. Key Words (Selected by Author(s)) } \\
\text { plate tectonics, crustal deformation, satellite laser } \\
\text { ranging. }\end{array}$} & \multicolumn{3}{|c|}{ 18. Distribution Statement } \\
\hline $\begin{array}{l}\text { 19. Security Classif. (of this report) } \\
\text { Unclassified }\end{array}$ & $\begin{array}{l}\text { 20. Security Class } \\
\text { Unclassified }\end{array}$ & if. (of this page) & 21. No. of Pages & 22. Price" \\
\hline
\end{tabular}

